\title{
A enunciação em primeira pessoa: o íntimo e o confessional em Adélia Prado
}

Laéria Bezerra Fontenele Universidade Federal do Ceará

\section{O eu como ator do discurso}

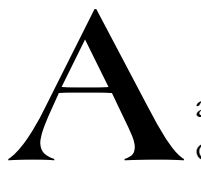

escritura de Adélia Prado tem, na instauração do eu como ator do discurso, uma das marcas de sua construção e modo de funcionamento. O que pode ser observado através de diversos expedientes da apresentação do eu no processo de significação: seu comparecimento como actante da enunciação; e sua expressão por meio da desinência verbal, que, pelo uso dos pronomes oblíquos e dos pronomes possessivos, fá-lo referente à primeira pessoa do verbo, conforme Fiorin (1999). Detectar a prevalência do eu, como o tipo de actorialização que recobre o foco narrativo da sua prosa e a voz lírica de sua poesia, é, antes de mais nada, perscrutar os efeitos que isso acarreta em termos de enunciação.

Ao se considerar, com Benveniste (1991), o estatuto que cada pessoa assume na conjugação, ver-se-á que o emprego do eu designa singularidade; ou seja, possibilita a construção da expressão que se liga a um agente específico, conferindo-lhe uma demarcação pessoal. O eu seria, sobretudo, o que vai se opor ao tu, fundando o pólo da subjetividade, que, por sua vez, contrapõe-se ao da não-pessoalidade, representada pela terceira pessoa do singular (ele). Florin:

Compartilhando com a mesma acepção de Benveniste, afirma .... eu e o tu são cada vez únicos, enquanto o ele pode ser uma infinidade de sujeitos ou nenhum. [...] Depois, o eu e o tu são reversíveis na situação de enunciação. No entanto, não é possível a 
reversibilidade com o ele. A terceira pessoa é a única com que qualquer coisa é predicada verbalmente. Com efeito, uma vez que ela não implica nenhuma pessoa, pode representar qualquer sujeito ou nenhum, e esse sujeito, expresso ou não, não é jamais instaurado como actante da enunciação. (1999, p. 58-59)

A reversibilidade eu-tu é condição para a construção do sujeito na esfera do discurso. É, ainda, o que permite ao eu colocar-se como tal; e, desse modo, designar o seu interlocutor, demonstrando que o eu do discurso não é um indivíduo; mas, sim, uma instância lingüística que agencia um modo de dizer.

De um outro ponto de vista, Paes contribui para a compreensão da utilização do eu na feitura do discurso literário ao demonstrar que o eu implica, necessariamente, a referência ao outro e que institui "o lugar por excelência da representação da outridade". (Paes, 1999, p.22) Dessa forma, não se poderia compreender a utilização textual de tal recurso estilístico sem a consideração de que, ao encontrar-se delimitado no literário, dáse a reprodução da própria gênese do eu como uma individualidade, organizada a partir da relação de espelhamento com o tu.

Com isso, ao dissolver um "eu" ilimitado, o "tu" o faz situar-se perante "o mundo de outros eus" (Paes, 1999, p.23) Daí a perspectiva, segundo a qual ( e nisso vê-se uma consonância com Émile Benveniste) a utilização da primeira pessoa como actante da enunciação não se reduz a um monismo experiencial: “... a experiência da outridade é portanto o avesso do solipsismo; é o caminho para a auto-avaliação crítica do eu”. (Paes, 1999, p.24)

Considerados esses aspectos, podem-se observar os efeitos de tal enunciação, promovida pela implementação de subjetividade e singularidade como figuras do dizer. Tais efeitos, no caso da escritura de Adélia Prado, são os do desdobramento entre o eu do Autor e o eu da enunciação; o dialogismo entre a voz lírica e o seu destinatário; a produção de um espaço e de uma temporalidade a partir da sua própria demarcação; e, por último, a colocação em ato de sua visibilidade.

Se é como instância lingüística que o eu funda o espaço do discurso, promovendo efeitos de significação, é, também, por meio dele que o eu da voz lírica e o eu do narrador são construídos como polaridades dialógicas que fundam a intersubjetividade. Esta, uma vez determinada, impossibilita que o discurso se feche numa subjetividade solipsa. Dessa forma, mesmo que o eu seja o centro do discurso, é a partir dele, como referência de localização, que tanto o outro como os objetos serão 
situados. Na medida em que a intersubjetividade é constituída segundo o espaço lingüístico, o eu só pode ser visto como instância limite entre o psíquico e o social. Será, portanto, através dela que se dará o seu reconhecimento como singularidade que se opõe ao outro.

O eu não pode reconhecer-se a si mesmo a partir de um mecanismo psicológico; mas, é por meio dessa ilusão que o eu edifica sua experiência social. Nela, encontra-se refletida a dimensão imaginária de sua constituição e as astúcias de sua expressão.

Mas, como o espaço discursivo do literário o faz comparecer em sua disjunção, o eu se manifesta, em sua condição de precário, expondo a sua impotência na formação de um saber universalizante e pondo a nu a ilusão de sua totalização; entanto, em Adélia Prado, é essa impotência mesma que assumirá um valor universal.

O fato de o eu dominar a cena do discurso adeliano dá a ele a aparência de um monólogo interior, de individualidade, de irredutível e de um segredo que se partilha num espaço reservado, sendo, por esse simulacro, que a sua escrita é tomada - pela crítica - como feminina; quando, em verdade, o espaço da interlocução, na enunciação poética da autora, já está implícito no próprio jogo que faz com que o eu do autor enuncie um eu do discurso literário. É, principalmente, sobre os vazios e os espaços de silêncio que se constroem os elos, através dos quais o eu do discurso procura dar sentido à sua própria colocação no ato da fala.

A aparência de monólogo interior - atribuída ao "discurso literário feminino" - atualiza a instância subjetiva do eu enquanto espaço ideológico, como simulacro de um saber que se constrói às custas da demarcação imaginária de uma pessoa; quando, em verdade, esta mesma pessoa, ao ser demarcada, na enunciação poética de Adélia Prado, revela muito mais a necessidade de deter a sua instabilidade na construção do sujeito do literário nos espaços de sociabilidade e, portanto, na esfera das relações simbólicas entre o discurso literário e aqueles com quem mantém relações de vizinhança.

A exemplo desse aspecto, está a recorrência, presente no livro Bagagem, do eu lírico situar-se a partir de seus referencias exteriores, quer os da vida ordinária, quer os de seus pares literários, como em "A invenção de um modo":

Entre paciência e fama quero as duas, pra envelhecer vergada de motivos. Imito o andar das velhas de cadeiras duras 
E se me surpreendem, explico cheia de verdade:

tou ensaiando. Ninguém acredita

e eu ganho uma hora de juventude.

Quis fazer uma saia longa para ficar em casa,

a menina disse: 'Ora, isso é pras mulheres de São Paulo'.

Fico entre montanhas,

entre guarda e vã,

entre branco e branco,

lentes para proteger de reverberações.

Explicação é para o corpo do morto,

de sua alma eu sei.

Estátua na igreja e praça

quero extremada as duas.

Por isso é que eu prevarico e me apanham chorando, vendo televisão,

ou tirando a sorte com que vou casar.

Porque tudo que invento já foi dito

nos dois livros que eu li: as escrituras de Deus,

as escrituras de João.

Tudo é Bíblias. Tudo é grande Sertão. (Prado, 1991 a:, p. 26)

Detendo sua instabilidade, por sua localização perante o outro, o eu pode, nesse poema, inscrever-se em relação à diversidade dos modos de significação.

Consoante com tal lógica - a da apropriação do outro pelo eu - são, igualmente, ilustrativos os seguintes versos do poema "Uma forma para mim":

\section{$[\ldots]$}

Uma vez, quando eu tinha quatro anos, achei um caco de vidro no monturo.

Lavei, enxagüei, guardei bem guardado e fui comer com vontade, ficar obediente, emprestar minhas coisas, por causa do caco, porque tinha ele, porque eu podia quando quisesse pôr ele contra o sol e aproveitar seu reflexo. Ele era laranjado chitadinho de branco. Assim eu sei, se assim puder, farei. Cada qual é diverso, descobri.

(Prado, 1991 a, p. 59)

A partir da posse dos restos, representados pelo "caco" catado do "lixo", o eu vislumbra-se através de seus reflexos; e, por esse procedimento, 
instaura a compreensão de que é possível constituir-se segundo a outridade, sem, no entanto, nela perder-se.

A enunciação do discurso poético ou ficcional em primeira pessoa promove, não raro, uma confusão quanto à identidade do sujeito enunciador. Neste universo de análise, - a escritura adeliana - coloca-se tal problema, na medida em que o próprio autor real do texto surge como personagem, confundindo-se, à primeira vista, com o sujeito do discurso, como se pode observar nos primeiros versos do poema "O sonho":

O reconheci na fração do meu nome, me chamou como em vida, a partir da tônica:

'Délia, vem cá'.

Peguei nos pés do catre, Onde jazia sã sua cara doente, e o fui arrastando por corredores cheios de médicos, seringas e uniformes brancos. Depois foi o dia inteiro o peito comprimido, sua voz no meu ouvido, seus olhos como só os dos mortos olham e a esperança, em puro desconforto e ânsia.

$$
\text { (Prado, 1991, p. 129) }
$$

Estes versos constituem a narração de um sonho por um "eu" identificado por meio da fração de um nome: "Délia". Na medida em que "Délia" narra um sonho já consumado, o eu se encontra fora do espaço e do tempo em que o devaneio se realizara; não é, portanto, o autor real que o revela, mas, sim, um autor que é construído, implicitamente, no intervalo das instâncias enunciativas do texto.

A respeito da necessidade de atentar a distinção entre o eu do autor e o eu que se imprime no texto, escreve Bakhtin, em sua teoria do romance:

É tão impossível a identificação absoluta do meu "eu" com o "eu" de que falo como alguém suspender a si mesmo pelos cabelos. O mundo representado, mesmo que seja realista e verídico, nunca pode ser cronotopicamente identificado com o mundo real representante, onde se encontra o autor criador dessa imagem. (Bakhtin, 1988. p. 360)

A problemática da responsabilidade pelos enunciandos e o questionamento da identidade entre representação e representante são, 
pois, centrais para a desconstrução das relações do eu com o autor real, mas, também, com o leitor real e o leitor produzido pelo movimento discursivo. Ao eu, como autor real, admite-se, conforme Pino, (1998. p.84) a "responsabilidade pela administração direta do espaço textual e indireta do espaço discursivo", enquanto que ao eu lírico caberia assumir a voz que fala no discurso.

O campo enunciativo é o espaço onde a voz lírica ganha expressão e imprime ao discurso uma direção que atinge o espaço representativo exterior ao discurso. É, neste espaço, que se localiza o "macro-espaço" cultural e semiótico que compreende o leitor.

O espaço representativo é, ainda, conforme Pino, (1998, p. 95) precisamente, no caso do discurso lírico, o espaço simbólico, em que se "dispõem e se organizam os elementos pré-constituídos no discurso". Estes serão fundamentais para o processo de construção do sentido, - objetivo que se coloca tanto do ponto de vista do discurso, quanto à sua organização interna, quanto do ponto de vista do seu pólo de interlocução.

É, a partir dessas multiplicidades, que as sugestões de sentido, construídas pelo eu do discurso, serão tomadas na análise desse aspecto na escritura de Adélia Prado. Especificamente, aí, o eu - como se pôde verificar inicialmente - situa-se de forma explícita, ocupando o centro da enunciação na sua condição de sujeito. É como instância produtora de fala que se apresenta de uma forma geral ao leitor: além de falar, o eu fala de si. A sua fala compreende, portanto, uma posição textual e uma posição simbólica.

Considerando-se as observações até aqui postas, far-se-á a análise de alguns dos poemas em que a voz lírica fala a partir da pessoa demarcada, para que se possam evidenciar tanto os aspectos peculiares a essa forma de enunciação quanto o modo por que se tece o entrecruzamento dos vários espaços que contribuem para a determinação da significação poética.

O primeiro aspecto, a ser considerado, refere-se à estreita ligação entre a voz lírica do eu e a própria construção do poético. Nesse caso, o eu assoma, no espaço do poema, como um elemento integrante do processo de significação a partir de sua insistência repetitiva e da sua alternância enquanto pessoa que fala e pessoa que vê; o que, por exemplo, focaliza o poema "Retrato": 
Eu quero a fotografia, os olhos cheios d'água sob as lentes, caminhando de terno e gravata, o braço dado com a filha.

Eu quero a cada vez olhar e dizer: estava chorando. E chorar.

Eu quero a dor do homem na festa de casamento, seu passo guardado, quando pensou:

a vida é amarga e doce?

Eu quero o que ele viu e aceitou corajoso, os olhos cheios d'água sob as lentes.

$$
\text { (Prado, 1991, p. 123) }
$$

O primeiro verso instaura, a partir do verbo querer, uma relação metonímica do que o eu é capaz de ver na cena fotografada. A imagem fotográfica é, então, descrita pelo eu da enunciação, que, ao fazê-lo, promove uma dupla temporalidade: a do eu que a quer e a do eu que dela participa, uma vez que cena enunciada.

A descrição das personagens da foto e a construção de uma cena dão ao eu o estatuto de narrador onisciente, capaz de fundar, através dos gestos e do olhar do pai da noiva, uma significação para o que ele viu e aceitou com coragem. Isto é reforçado pelo verso a ele anterior, onde o eu narrador delega o ato de fala ao personagem: "a vida é amarga e doce?". O eu que quer caminha em direção ao objeto de seu querer num movimento posterior àquele que lhe possibilitou vislumbrar, na fotografia, a dor que permeia os movimentos de ultrapassagem que a vida compreende e a atitude de reconhecer a sua dimensão contraditória e irredutível. A alternância do eu que quer e a do eu que vê promove a inversão da temporalidade do fato representado no poema, criando a temporalidade do poético.

Ao enunciar o seu "querer", construindo, com isso, uma fala sobre si mesmo enquanto desejante, o eu o faz transformando as formas enunciativas. Observa-se, nessa estratégia, o procedimento descrito por Lozano, Peñia - Marin \& Abril (1993, p.126): "Los comentarios sobre sí mismo son un caso de comutation actancial, que usualmente es señalada com cambios en las formas enunciativas ( referentes a la modalidad, la persona, el espacio y el tiempo)".

A isso também se relaciona a onisciência do sujeito lírico ao enunciar algo relativo ao outro. Vê-se, a partir de Harré y Secord, (1972) 
que ocorre na medida em que: "La capacidad de hacer comentarios sobre sí miesmo implica que el comentador tenga una perspectiva exterior al campo de lo comentado" (p. 136)

Um aspecto que se segue a este é o da produção, através das posições do eu na construção do sentido, de uma espacialidade dos diversos olhos que têm a faculdade de ver, o que permite a instauração das visibilidades, postas no movimento enunciativo: o olho do eu vê o mesmo que o olho da personagem. A fotografia figura a superfície refletora de um olhar do eu, que vê o Outro por um movimento identificatório, - aquilo a que reconhece como objeto de seu querer.

Esses espaços somente se potencializam como tais a partir de um outro olho que está fora do texto, mas é condição da instauração do objeto fotografia. Trata-se do olho que condensa a máquina fotográfica e o de quem fotografa. Um olho simbólico que, anterior a todas as temporalidades em que aparece o eu, é sua condição de produção: espaço capaz de integrar outros espaços e as mais diversas temporalidades, decorrentes do deslizamento e do desdobramento da voz lírica, enquanto eu no advento do sentido poético por seu movimento de retroação significante.

Inúmeros são os poemas em que o eu lírico anuncia-se como actante da descrição de uma cena, de um lugar, de um sonho, de uma coisa ou de uma pessoa. E o faz como se fora seu espectador, para, em seguida, integrar-se ao que é descrito, passando, também, a exercer uma ação no contexto.

Tal participação do eu, como integrante do discurso, promove uma quebra de sentido, inaugurando, assim, uma abertura, para que se estabeleçam o processo de significação e o seu concomitante efeito poético. Ao descrever uma cena e, também, vivenciá-la, o eu vem a se constituir o núcleo organizador da experiência estética da voz lírica que, por descentrar-se, engendra o sentido poético.

O poema "Leitura" é uma foram desse comparecimento do eu:

Era um quintal ensombrado, murado alto de pedras.

As macieiras tinham maçãs temporãs, a casca vermelha

de escuríssimo vinho, o gosto caprichado das coisas

fora do seu tempo desejadas.

Ao longo do muro eram talhas de barro.

Eu comia maçãs, bebia a melhor água, sabendo

que lá fora o mundo havia parado de calor.

Depois encontrei meu pai, que me fez festa 
e não estava doente e nem tinha morrido, por isso ria, os lábios de novo e a cara circulados de sangue, caçava o que fazer pra gastar sua alegria: onde está meu formão, minha vara de pescar, cadê minha binga, meu vidro de café? Eu sempre sonho que uma coisa gera, nunca nada está morto.

O que não parece vivo, aduba.

O que não parece estático, espera.

$$
\text { (Prado, 1991, p. 19) }
$$

O primeiro movimento do poema - do verso 1 ao verso 5 - implica o espaço representacional, onde o eu goza a visibilidade das coisas "fora de seu tempo desejadas" e as enuncia. Nesses versos, o narrador do sonho põe em destaque o lugar e as coisas nele contidas como signos de sua singularidade. O quintal - termo referente a uma terceira pessoa - aparece como inverso ao eu. Não se sabe, através de sua descrição, como lugar reportado ao espaço lingüístico, que se trata de um lugar onde se expressa o sujeito onírico.

O segundo movimento compreende os versos 6 e 7; nele, o eu se localiza, através do espaço da linguagem, num lugar objetivo (o quintal, que se contrapõe ao "mundo lá fora" como signo da esfera social) e num outro subjetivo, onde desfruta as coisas representadas em sua singularidade. É através dessa localização que se pode produzir, num só depois, o efeito de significação que permite localizar todo o espaço do poema como onírico.

Foram os versos 09 e 14 - integrantes do terceiro movimento desse poema - que operaram, retroativamente, contaminando os espaços anteriores com a marca da lógica onírica. O terceiro movimento, do verso 8 ao 17, flagra o eu em seu puro descentramento, ao descrever a realidade onírica como um outro espaço de expressão, no qual o eu se converte em sujeito desejante.

Entre o primeiro e o terceiro movimento, ocorre a queda do eu como unidade representacional de uma identidade psicológica e social, fechada e determinada pelo contágio da consciência pelo real. Dissolvese, com isso, a oposição experiência pessoal, experiência social e experiência onírica, dando lugar à sua integração na apreensão do real, cuja marca, no poema, é o jogo de oposições: "O que não parece vivo, aduba./ O que não parece estático, gera.” 
Se na mobilidade de apresentação do eu, a voz lírica faz intervir a vOz de outrem, enquanto espaço de interlocução simbólica, observa-se a diferença do acesso ao real, não mais pelo seu pólo representacional ou desejante, mas pelo poder da intervenção da escuta e da palavra, como figuras do simbólico, capazes de fazer com que o eu transponha os limites imaginários da sua experiência, ao deparar os limites da interlocução entre o eu e outro, conforme a leitura do poema "No meio da noite":

Acordei meu bem pra lhe contar meu sonho:

sem apoio de mesa ou jarro eram

as buganvílias brancas destacadas de um escuro.

[...]

Doía como um prazer.

Vendo que eu não mentia ele falou:

as mulheres são complicadas. Homem é tão singelo.

Eu sou singelo. Fica singela também.

Respondi que queria ser singela e na mesma hora, singela, singela, comecei a repetir singela.

A palavra destacou-se novíssima como as buganvílias do sonho. Me atropelou.

- O que foi? - ele disse.

- As buganvílias...

Como nenhum de nós podia ir mais além, solucei alto e fui chorando, chorando, até ficar singela e dormir de novo.

(Prado, 1991, p. 17)

Nesse poema, a palavra do outro emerge como uma armadilha para o eu que constrói o desdobramento poético do sonho relatado. A face imagético-sonora da palavra "singela" destaca-se e atropela o eu. A partir disso, o eu lírico faz emergir, como uma conseqüência semântica, a identificação entre as "buganvílias" do sonho e a palavra "singela".

O deslizamento do significado pode ser apreendido, nesse caso, segundo a delimitação da esfera material da linguagem como potência transformadora e como limite dialógico, como uma espécie de núcleo de pedra em que esbarra a interdiscursividade, - zona de silêncio onde o indizível se expressa através dos efeitos materiais do significante "buganvílias".

Outra forma de instalação de um espaço de interlocução entre o eu lírico e o outro, é o da intervenção da enunciação do leitor implícito, a 
quem o eu lírico faz de destinatário do seu dizer, consoante os versos de "Objeto de amor":

De tal ordem é e tão precioso

o que devo dizer-lhes

que não posso guardá-lo

sem que me oprima a sensação de um roubo:

cu é lindo!

Fazei o que puderdes com esta dádiva.

Quando a mim dou graças

Pelo que agora sei

E, mais que perdôo, eu amo.

(Prado, 1991, p. 319)

A tônica confessional, como artifício expressivo do eu lírico, revela a preocupação com o leitor como outro social da experiência estética. Com ele, o eu-lírico estabelece uma relação, não apenas de destinatário de uma mensagem, mas, sobretudo, um compromisso ético na partilha dessa experiência, decorrendo daí o seu caráter simbólico de revelação.

O eu lírico, em relação ao "possível" leitor, coloca-se no lugar de quem conhece um segredo, detém um saber sobre a coisa e tem a obrigação de a ele tudo isso transmitir. Enunciar um saber, antes nãosabido, revela-se ao eu lírico como a dádiva de preencher, com o sentido poético, algo que o cotidiano e os usos ordinários da língua esvaziaram de sentido.

É somente na medida em que lhe é objeto da expressão poética que tal saber pode circular socialmente através de sua partilha simbólica com o leitor. O eu lírico é construído pela Autora como o enunciador do que a ela se impõe como função mediadora entre a apresentação da coisa e a sua circulação enquanto palavra plena de significação.

\section{O mínimo eu: a dicção adeliana}

Nos poemas analisados até o momento, bem como em inumeráveis outros, é de fundamental importância a compreensão de que não basta ao eu lírico, simplesmente, demarcar o seu lugar perante o outro e o mesmo. Sua localização no mundo imprime-se como dado da experiência poética. 
Se a tradição poética moderna atualiza a relação do eu lírico com o mundo, ordenado a partir dos avanços da técnica e dos processos de modernização como um todo, conforme Friedrich (1978), Adélia Prado, ao contrário, atualiza a província como lugar, a partir do qual o eu lírico expressa a sua vivência cotidiana.

Essa estratégia de reportar para o espaço lingüístico o lugar da "província" faz parte da estruturação de sua obra e tem, por conseqüência, a demarcação do eu e dos lugares em que se dará o seu modo de articulação social. As práticas, os modos de fazer e de agir, edificadores desse cotidiano, comparecem ao poético como condição e matéria da expressão do eu no mundo, e não como consciência de saber-se vítima da modernidade.

O eu lírico, além de situar-se na província como espaço microfísico, efetua a sua divisão ao atualizar lugares cada vez mais circunscritos, tais como: a pensão: "Na sala de janta da pensão/ tinha um jogo de taças roxoclaro.”; (Prado, 1991, p. 16) a igreja: "a igreja é o melhor lugar./ Lá o gado de Deus pára pra beber água...”; (Prado, 1991, p. 74) o jardim: "Nasceu no meu jardim um pé-de-mato/ que dá flor amarela"; (Prado, 1991, p. 67) a cozinha: "Minha mãe cozinhava exatamente:/ arroz, feijão-roxinho, molho de batatinhas..."; (Prado, 1991, p. 151) o quintal: "Era um quintal assombrado, murado alto de pedras"; (Prado, 1991, p. 19) o quarto: “...parei no meio do quarto, uma lucidez tão grande..."; (Prado, 1991,p. 39) ou, até mesmo, um não-lugar que se projeta através da rememoração do lugar perdido, - sendo este, também, dividido:

Eu já tive e perdi

uma casa

um jardim

uma soleira

uma porta

um caixão de janela com um perfil...".

(Prado, 1991, p. 105)

Os lugares divididos e circunscritos indicam, num primeiro momento, a recusa do eu lírico pela sua abstração espacial, reportando para o poético um eu que sente o mundo e dele é ator; num segundo momento, possibilita o reconhecimento de que o mínimo de sua experiência é, ao mesmo tempo, o que lhe confere uma referência ao todo. 
Nessa operação de divisão, não se observa a dialética lugar / nãolugar, presente num tipo de configuração dos espaços constituintes das metrópoles, que, por se afastarem da temporalidade natural, recriam-na artificialmente, de acordo com os usos que desses lugares podem ser feitos. Assim, a localização do eu pode ser apreendida pela posição adotada pelo sujeito da significação poética em situar-se em relação ao todo segundo uma dupla posição: a que lhe possibilita o acesso ao nãotodo, condicionada pela dimensão mística de um sujeito que fala consoante uma demarcação de gênero; e a que lhe proporciona o acesso ao todo, - esta mediada pela possibilidade do sujeito lírico viabilizar-se enquanto tal no domínio do poético, que, por sua vez, requer a posição de desejante, ou seja, de partícipe dos sentidos simbólicos que o sistema literário veicula, ampliando-lhes a dimensão sem alterar-lhes os signos.

\section{O lugar do mínimo no todo do espaço social}

Se os lugares obedecem à lógica da divisão, a eles é também facultada a operação inversa, possibilitando-lhe a localização no todo do espaço social. Dessa forma, surge como questão se o fato de que o eu da enunciação, ao afirmar a sua localização, não estaria descartando a indagação "onde estou?", como signo da desterritorialização, a que o sujeito está submetido na modernidade, do qual o exemplo mais paradigmático é o de Proust, conforme leitura de Poulet, (1992) configurando, na escrita moderna, a angústia diante do mundo? Não seria, também, uma forma de fornecer ao cotidiano, enquanto signo do caráter atmosférico do banal, a conotação de lugar fronteiriço entre o objetivo e o subjetivo da experiência do eu lírico?

O poema "Janela" aponta importantes elementos para a discussão acerca da particularidade da relação eu - mundo, enquanto índice do espaço discursivo na poesia de Adélia Prado:

Janela, palavra linda.

Janela é o bater das asas da borboleta amarela.

Abre pra fora as duas folhas de madeira à-toa pintada, janela jeca, de azul.

Eu pulo você pra dentro e pra fora, monto a cavalo em você, meu pé esbarra no chão.

Janela sobre o mundo aberta, por onde vi 
o casamento de Anita esperando neném, a mãe do Pedro Cisterna urinando na chuva, por onde vi meu bem chegar de bicicleta e dizer a meu pai: minhas intenções com sua filha são as melhores possíveis. Ô janela com tramela, brincadeira de ladrão, clarabóia na minha alma, olho no meu coração.

$$
\text { (Prado, 1991, p. 103) }
$$

Nesse poema, o significante "janela" é acentuado quanto à sua beleza sonora e conceituado a partir de seu uso: o movimento de abrir e fechar. A referência ao movimento em direções opostas (dentro e fora) implica observar a janela como um lugar, cuja característica é o da demarcação de uma fronteira.

$\mathrm{Na}$ construção da significação poética, a alusão à imagem em movimento é acrescida do próprio movimento do eu lírico, que se enuncia transpondo a janela para dentro e para fora; o que o situa nem dentro e nem fora dela, mas na sua barra, no limite ("monto a cavalo em você") a partir do qual situa-se, também, no mundo.

A partir do verso "meu pé esbarra no chão", quebra-se o efeito de sentido do movimento, instaurando-se o da visibilidade, fruto da observação do que se passa para além da janela. Ao construir as cenas imagéticas do que pode ver através da janela, o eu lírico constrói, também, a si mesmo como imagem: a de um sujeito que vê a si e ao outro, a partir de sua capacidade de empreender um deslocamento, que, no entanto, é demarcado pelo chão.

É por situar-se aí que o sujeito da significação emerge desdobrado no dentro e no fora, pela sua imagem e a do outro. Tal posição rompe com o equívoco que toma a imagem apenas como objeto da percepção de um observador. Nesse poema, a imagem vista inclui aquele que a vê.

O recobrimento de uma imagem por outra revela o mecanismo de base da construção das subjetividades, que consiste na prevalência do imaginário, das máscaras da moralidade social, sobre a significação simbólica das sociabilidades em jogo. Por isso, a bisbilhotice do eu lírico, anunciando cenas das quais não participa ou denunciando o que os outros procuravam esconder por conta das conotações de atos "proibidos socialmente".

Essa forma, assumida pelo eu lírico, é, por outro lado, o que lhe permite pôr a nu a incoerência do outro social, ao procurar encobrir a sua inadequação às exigências que lhes são feitas pela moralidade social. A 
natureza das imagens produzidas denuncia o movimento identificatório do observador com o que é percebido, contando-se como mais um dos atores do mundo, assumindo, com isso, a impossibilidade de transpor os limites ideológicos de sua própria subjetividade.

Assim, é a partir desse posicionamento no espaço lingüístico que o eu da enunciação poética, em Adélia Prado, define sua temporalidade e, também, ordena-a como função do discurso. O artifício de fundar um centro gerador, - um aqui e agora -, no espaço da enunciação, é condição de sua especificidade, mas é, também, o desmonte da ilusão que essa posição representa. O agora, que a enunciação procura produzir, é, conforme se vê no poema, sempre uma construção prévia ao ato da enunciação. Em conseqüência disso, a temporalidade de sua inserção no mundo do discurso é uma tentativa de dar conta da heterogeneidade de sua própria expressão e de sua materialidade tópica, a de se localizar no mundo e para além dele: a visibilidade do mundo é condição de sua visibilidade subjetiva.

A idéia do mundo como espetáculo de contradições e núcleo gerador de angústias do eu lírico, que Affonso Romano de Sant'Anna (1980) identifica como modo de sua espacialidade na literatura contemporânea, é subvertida no espaço lingüístico da lírica de Adélia Prado, pois, nela, a demarcação do eu como pessoa do discurso não permite a sua oposição conflituosa com a realidade exterior; tampouco, entre sujeito e objeto. A oposição entre eu e realidade é, sobretudo, a oposição do eu em relação a seu espaço de enunciação, o que a torna o limite mesmo da interdiscursividade entre o eu e o mundo.

Assim sendo, não é pela condição de voyeur do mundo que o eu se constrói no espaço discursivo aqui analisado, e, sim, pelo seu deslocamento, repetições e retornos quanto a si como sujeito e objeto do mundo. Nessa dupla condição, o eu é aquele que vive e sofre a impossibilidade dessa síntese. Por isso, tem que "desdobrar-se", abandonando o "gosto cabotino da tristeza", ${ }^{1}$ para cultivar a expressão poética do que se encontra banalizado na esfera do cotidiano. O mundo pede ao eu lírico que lhe dê expressividade poética, e este se desdobra nessa produção; mas é no chão do cotidiano, todavia, que ele apóia o pé para dar conta dessa tarefa.

${ }^{1}$ Esse gosto é associado à personagem gauche, em Carlos Drummond de Andrade, como protótipo de sua atitude cosmogônica. Conferir em Sant'Anna (1980. p. 36). 
As contradições, alteridades e diferenças são assumidas como positividades, a partir das quais o sentido poético pode ser manifestar. São, ainda, o que possibilita a síntese, na produção literária de Adélia Prado, dos domínios da escrita - em seu enraizamento e caráter de fechamento - e da fala coloquial, em seu movimento de usura das palavras e em seu caráter de abertura.

A subjetividade do eu, decorrente dessa posição, não autoriza a sua assimilação apenas ao domínio do incomunicável; mas, sim, a um duplo registro, no qual coabitam o eu e o outro, o sentido e o sem-sentido, a parte e o todo, o humano e o divino, o corpo e a alma. Por isso, a forma confessional da escritura adeliana não poder ser reconhecida como "uma escrita essencialmente privada, cuja especificidade é o segredo", (Miranda, 1992, p. 34) à semelhança de um diário.

É, apenas, na medida em que objetiva comunicar algo ao leitor, que essa função se mantém; sofre, em verdade, uma dissolução, pois o segredo torna-se público, mantendo-se apenas o silêncio que lhe permitiu a revelação, mas não o seu mutismo. O confessional adeliano é, antes de tudo, eticidade. Como tal, admite a indagação (a rigor, afirmativa) de Suberchiot (1998, p. 53): "Qu'est ce que le sens pour un poète sinon la présence en lui de l'autre?”.

\section{Referências Bibliográficas}

BAKHTIN, Mikhail. Questões de literatura e de estética. (A teoria do romance). 4. ed. Trad. Aurora Fornoni Bernadini et al. São Paulo: Unesp, 1998.

BENVENISTE, Émile. Problemas da lingüistica geral. Campinas: Pontes, 1994. FIORIN, José Luiz. As astúcias da enunciação. As categorias de pessoa, espaço e tempo. 2. ed. São Paulo: Ática, 1999.

FRIEDRICH, Hugo. Estrutura da lírica moderna: da metade do século XIX a meados do século XX. Trad. Marise M. Curioni et al. São Paulo: Duas Cidades, 1978.

HARRÉ. R.; SECORD, P. F. La spiegazione del comportamento sociale. Bolônia: Il Mulino, 1979.

LOZANO, Jorge; PEÑA-MARIN, Cristina; ABRIL, Gonzalo. Análisis del Discurso. Hacia una semiótica de la interacción textual. México: Rei Mexico, 1993. 
MIRANDA, Wander M. Corpos escritos: Graciliano Ramos e Silviano Santiago. .São Paulo: Edusp. Belo Horizonte: Editora UFMG, 1992.

PAES, José Paulo. O lugar do outro. Ensaios. Rio de Janeiro: Topbooks, 1999. PÊCHEUX, Michel. Semântica e discurso. Uma crítica à afirmação do óbvio. 2. ed. Trad. Eni Pulcinelli Orlandi et al. São Paulo: Editora da Unicamp, 1995. PINO, D. Espaço e textualidade. Quatro estudos quase semióticos. Porto Alegre: Mercado Aberto; São Leopoldo (RS): UNISINOS, 1998.

POULET, Georges. O espaço proustiano. Trad. Ana Luiza B. Martins Costa. Rio de Janeiro: Imago, 1992.

PRADO, Adélia. Poesia reunida. São Paulo: Siciliano, 1991.

SANT'ANNA, Affonso Romano de. Carlos Drummond de Andrade: análise da obra. 3. ed. Rio de Janeiro: Nova Fronteira, 1980.

SUBERCHICOT, Alain. Treize façons de regarder Wallase Stevewns. Une écriture de la présence. Paris: L’Harmattan, 1998.

\section{Resumo}

Estudará a enunciação em primeira pessoa na escritura de Adélia Prado. Discutirá as relações entre o autor real e o autor do texto literário, realizando, além disso, a análise de alguns dos poemas representativos da anunciação desse discurso. Trabalhará o estatuto do confessional e do íntimo na veiculação da verdade poética, e a correlação desse eu com a produção do poético.

\section{Résumé}

On étudiera l'emploi de l'ennonciation dans la première personne chez Adélia Prado. On discutera les rapports entre l'auter réel et l'auter du texte littéraire. On cherchera en plus à realiser l'analyse de quelques poèmes surtout les plus représentatifes de l'annonciation de ce type de discours. On travaillera de statut du confessionel et de l'intime dans la transmission de la verité poétique et la correlation de ce je dans la production du poétique. 